\title{
INFLUENCE OF THE AIR LAYER BETWEEN THE CONDUCTOR AND THE LAYER OFINSULATING MATERIAL IN CABLE PRODUCTS
}

\author{
Evgenia V. Ivanova ${ }^{1, a}$, Olga S. Yashutina ${ }^{1}$, StanislaV. Shidlovskiy ${ }^{2}$ \\ ${ }^{1}$ National Research Tomsk Polytechnic University, 634050 Tomsk, Russia \\ ${ }^{2}$ National Research Tomsk State University, 634050, Tomsk, Russia
}

\begin{abstract}
There are developed mathematical model of physical and chemical processes of polymerization adhesive coating stranded cable. There are shown difference in the temperature distribution along the radius of the finished product in the presence of an air gap between the conductor and the rubber sheath. Also, due to the need to change process parameters with possible loose contacts inside the cable. Such as the temperature of the heating surface, feeding speed and dwell time in the oven.
\end{abstract}

\section{Introduction}

Production of cables is a long and energy-intensive process. The result is a whole product length of 100 meters. In this case, even a small marriage invalid. It is believed that contact between the conductor and the layer of insulating material of the finished cable product is ideal, in shell tightly to the copper conductor. Acceptable dimensions of gaps, as a rule, does not exceed $0.01 \mathrm{~mm}$ [1].

The aim of this study was to determine the possible impact of the presence of the air layer between the copper wire and the rubber shell, exceeds the limit, the polymerization on the final products of the cable sheath.

\section{Problem statement}

Numerical simulation was carried out in the system shown in Fig. 1. It was assumed that the cable consists of a copper conductor, an air layer and a rubber sheath. Considered axial symmetric system.

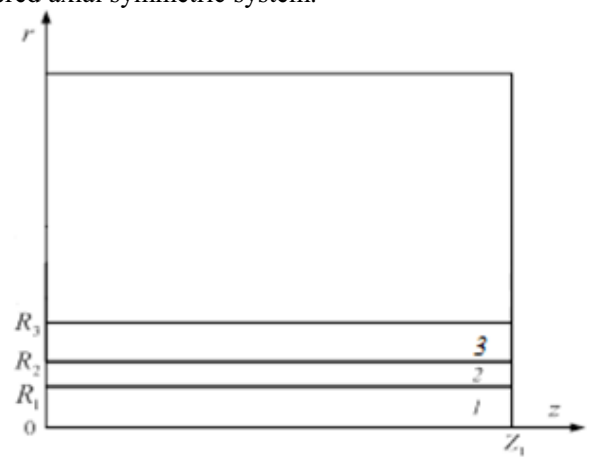

Figure 1. Schematic of the field of solving the problem: 1 - steel wire, 2 - air layer 3 - cable sheath.

In the numerical simulation used the following assumptions do not impose significant restrictions on the common statement of the problem:

1. The cable has a right cylindrical shape.

2. We consider a fragment of a perfectly insulated cable end.

3. The thermal characteristics of the material strands, the cable sheath and the air in the heating chamber does not depend on temperature.

4. The activation energy of the polymerization process is constant with temperature.

5. The cable is stationary relative to the camera.

${ }^{a}$ Corresponding author: zhenya1@tpu.ru

This is an Open Access article distributed under the terms of the Creative Commons Attribution License 4.0, which permits unrestricted use, distribution, and reproduction in any medium, provided the original work is properly cited. 


\section{EPJ Web of Conferences}

\section{Mathematical model}

A mathematical model of heat and mass transfer system "hot air - cable" in a cylindrical coordinate system (Fig. 1$)$ for $0<\mathrm{t}<\mathrm{t}_{\mathrm{p}}$ can be formulated in the form of a typical stationary differential equations of mathematical physics [2, 3].

The heat equation for the core $\left(0<\mathrm{r}<\mathrm{R}_{1}, 0<\mathrm{z}<\mathrm{Z}_{1}\right)$ :

$$
\rho_{1} C_{1} \frac{\partial T_{1}}{\partial t}=\lambda_{1}\left(\frac{\partial^{2} T_{1}}{\partial r^{2}}+\frac{1}{r} \frac{\partial T_{1}}{\partial r}+\frac{\partial^{2} T_{1}}{\partial z^{2}}\right)
$$

The heat equation for the air layer $\left(\mathrm{R}_{1}<\mathrm{r}<\mathrm{R}_{2}, 0<\mathrm{z}<\mathrm{Z}_{1}\right)$ :

$$
\rho_{2} C_{2} \frac{\partial T_{2}}{\partial t}=\lambda_{2}\left(\frac{\partial^{2} T_{2}}{\partial r^{2}}+\frac{1}{r} \frac{\partial T_{2}}{\partial r}+\frac{\partial^{2} T_{2}}{\partial z^{2}}\right) .
$$

The energy equation for the insulating sheath $\left({ }_{\mathrm{R} 2}<\mathrm{r}<_{\mathrm{R} 3}, 0<\mathrm{Z}<\mathrm{Z}_{1}\right)$ :

$$
\begin{gathered}
\rho_{3} C_{3} \frac{\partial T_{3}}{\partial t}=\lambda_{3}\left(\frac{\partial^{2} T_{3}}{\partial r^{2}}+\frac{1}{r} \frac{\partial T_{3}}{\partial r}+\frac{\partial^{2} T_{3}}{\partial z^{2}}\right)+q_{3} \rho_{3} \frac{d \varphi_{3}}{d t} ; \\
\frac{d \varphi_{3}}{d t}=\left(1-\varphi_{3}\right) k_{3}^{0} \exp \left(-\frac{E_{3}}{R_{\mathrm{t}} T_{3}}\right) .
\end{gathered}
$$

The initial $(\mathrm{t}=0)$ conditions:

$\mathrm{T}=\mathrm{T}_{0}$ at $0<\mathrm{r}<\mathrm{R}_{3}, 0<\mathrm{Z}<\mathrm{Z}_{1}$;

$\varphi=\varphi_{0}$ at $\mathrm{R}_{2}<\mathrm{r}<\mathrm{R}_{3}, 0<\mathrm{z}<\mathrm{Z}_{1}$.

The boundary conditions at $0<\mathrm{t}<\mathrm{t}_{\mathrm{p}}$ :

$\frac{\partial T}{\partial z}=0$ at $\mathrm{z}=0,0<\mathrm{r}<\mathrm{R}_{3} ; \mathrm{z}=\mathrm{L}, 0<\mathrm{r}<\mathrm{R}_{3} ;$

$\frac{\partial T}{\partial r}=0$ at $\mathrm{r}=0,0<\mathrm{z}<\mathrm{Z}_{1} ; \mathrm{r}=\mathrm{R}_{3}, 0<\mathrm{z}<\mathrm{Z}_{1} ;$

$-\lambda_{1} \frac{\partial T_{1}}{\partial r}=-\lambda_{2} \frac{\partial T_{2}}{\partial r}, T_{1}=T_{2}$ at $\mathrm{r}=\mathrm{R}_{1}, 0<\mathrm{z}<\mathrm{Z}_{1} ;$

$-\lambda_{2} \frac{\partial T_{2}}{\partial r}=-\lambda_{3} \frac{\partial T_{3}}{\partial r}, T_{2}=T_{3}$ at $\mathrm{r}=\mathrm{R}_{2}, 0<\mathrm{z}<\mathrm{Z}_{1}$.

The system of non-stationary differential equations with appropriate boundary conditions is solved by finite difference method [4]. Difference analogs of differential equations solved locale-no-one-dimensional method and variable direction [4]. To solve the two-dimensional difference equations applied sweep method using a four-point implicit scheme [4].

\section{Results and discussion}

It can be seen that the presence of the air layer, exceeding the limit value considerably influences the temperature distribution along the radius of the finished product (Fig.2). The surface of the cable is heated to considerably higher temperatures, which can lead to burnout of the shell. Also, due to gapping may be incorrectly selected process parameters (time, speed of pulling, the temperature of the heating surface), which in turn may affect the polymerization of the shell.

It is necessary to control the fit sheath to core in the manufacture of cable products to improve the quality of the finished product (the degree of polymerization of the rubber should be close to 1). 
Thermophysical Basis of Energy Technologies 2015

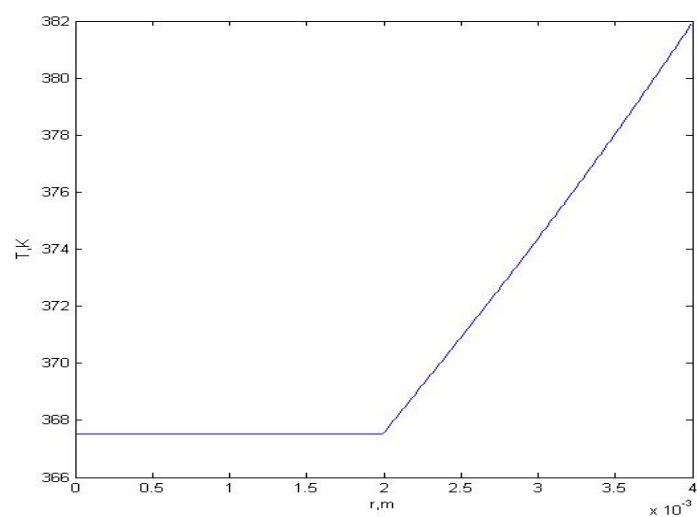

a)

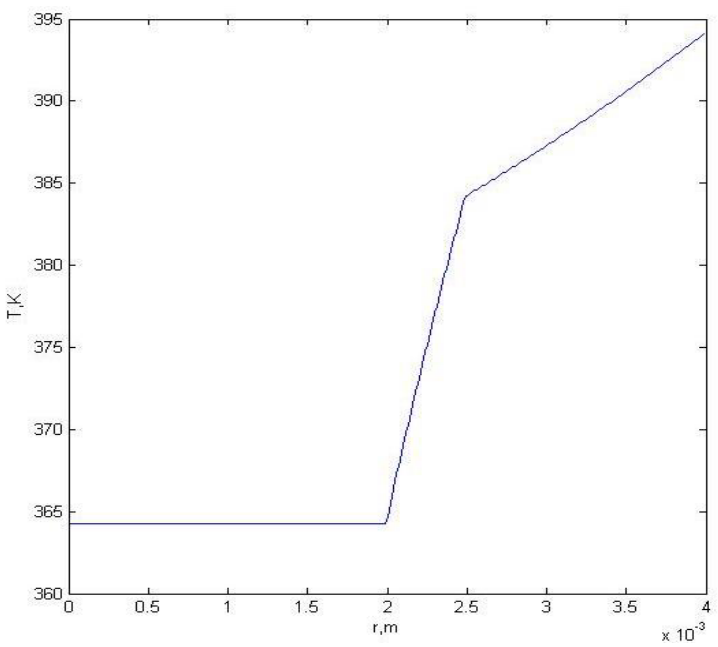

б)

Figure 2. Distribution of temperature: a) without an air layer between the sheath and conductor, b) in the presence of the air layer of $0.5 \mathrm{~mm}$.

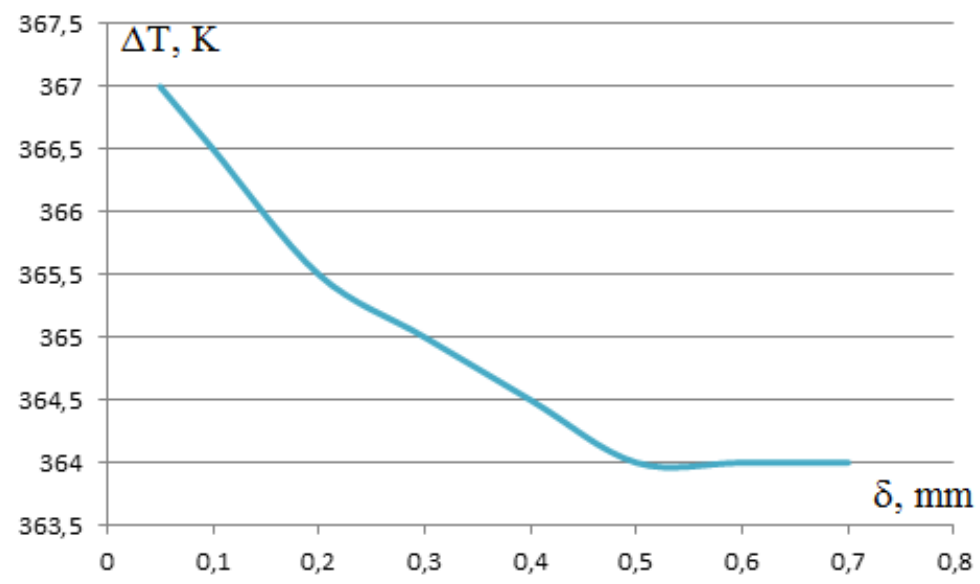

Figure 3. Temperature dependence of the copper wires in the center of cable products from the thickness of the air layer. 


\section{EPJ Web of Conferences}

\section{Conclusion}

The developed mathematical model, algorithms for the numerical solution of heat and mass transfer can be used to analyze the quality of the insulation of cable products and energy efficiency of polymerization processes in their production [5-9]. Also, the proposed model can be used as predictive modes when selecting curing typical cables and the relevant parameters (temperature in the furnace, the heating time, pull the speed, etc.).

This work was supported by the Russian Foundation for Basic Research (project 14-08-00057).

\section{References}

1. V.M. Leonov, I.B. Peshkov, I.B. Ryazanov, Cold, SD Fundamentals of cable technology (M .: publishing center “Academy”, 2006).

2. P.J. Roach, Computational fluid dynamics (M .: Mir. 1980)

3. Y. Dzhaluriya, Natural Convection: Heat - and mass transfer (M .: Mir. 1983)

4. A.A. Samarskiy, The theory of difference schemes (M.: Nauka. 1983)

5. E.V. Ivanova, G.V. Kuznetsov, Chem. Pet. Eng., 7, 10 (2011)

6. E.V. Ivanova, G.V. Kuznetsov, Journal Of Chemical and Petroleum Engineering, 47 (7-8), 447 (2011)

7. E.V. Ivanova, G.V. Kuznetsov, P.A. Strizhak, EPJ Web of Conferences, 76, 01024 (2014)

8. E.V. Ivanova, M.M. Grigorieva, P.A. Strizhak, EPJ Web of Conferences, 82, 01031 (2015)

9. E.V. Ivanova, G.V. Kuznetsov, P.A. Strizhak, Journal Of Chemical and Petroleum Engineering, 51 (3-4), 164 (2015) 